\title{
Scalable Synchronous Cohort-Based International Education
}

\section{Dr. Tilman Wolf, University of Massachusetts, Amherst}

Tilman Wolf is Professor of Electrical and Computer Engineering and Senior Vice Provost for Academic Affairs at the University of Massachusetts Amherst. As Associate Dean of Engineering, he led major initiatives in the College of Engineering, including the establishment of a new Department of Biomedical Engineering and its degree programs, implementation of a new cohort-based distance education M.S. program, and development of a training program for graduate students who teach the college-wide freshman seminar. He is engaged in research and teaching in the areas of computer networks, cybersecurity, and embedded systems.

\section{Dr. C. V. Hollot, University of Massachusetts, Amherst}

C.V. Hollot received his Ph.D. in Electrical Engineering from the University of Rochester in 1984 after which he joined the ECE Department at the University of Massachusetts Amherst where he is presently Department Head. His research interests are in the theory and application of feedback control.

\section{Russell Tessier, University of Massachusetts Amherst}

Russell Tessier received the B.S. degree in computer and systems engineering from Rensselaer Polytechnic Institute, Troy, NY in 1989, and the S.M. and Ph.D. degrees in electrical engineering from the Massachusetts Institute of Technology, Cambridge, MA, in 1992 and 1999, respectively. He is currently Professor of Electrical and Computer Engineering at the University of Massachusetts, Amherst. His current research interests include computer architecture and field-programmable devices.

\section{Mr. George Bryan Polivka, Shorelight}

Bryan Polivka is currently the Senior Director for Shorelight Education, focused on instructional design and learning architecture. He has helped schools, universities, corporations, and nonprofits with strategy and strategically positioned product. He and his teams have built online, hybrid, and live distance programs for and with a long list of universities including UMass Amherst, Harvard, Wharton, Johns Hopkins, Stanford, Berkeley, Carnegie-Mellon, the University of Liverpool, and Universidad del Valle de Mexico. Awards include Most Significant Achievement from the US Distance Learning Association, and a national Emmy for a documentary he wrote and produced.

\section{Prof. Yadi Eslami}

Dr. Yadi Eslami is a senior lecturer at the ECE department of UMASS Amherst. He is the coordinator and an instructor of the Field Degree program. Before joining UMASS Amherst he has been an assistant professor at West Virginia University Institute of Technology. His industrial experience includes working as a design engineer at DRAM R\&D, Micron Technologies Inc., Boise, Idaho, and as a system design engineer at SciTech AAG, Inc., in Toronto, Ontario. He has several articles and presentations in refereed journals and conferences and holds four patents on DRAM and FeRAM circuits. His research interests are reconfigurable processor architectures, special-purpose processors, embedded systems, and VLSI memories. 


\title{
Scalable Synchronous Cohort-Based International Education
}

\begin{abstract}
In the highly competitive market for international graduate students, universities have aimed to reach students via asynchronous online programs or by establishing branch campuses. To address the quality concerns and costs of these approaches, recent work has demonstrated a novel instructional technology that enables synchronous, interactive instruction to international students. In this work, we report on our efforts to increase the scalability of this approach. Specifically, we present our new approach of teaching synchronously to multiple classrooms in parallel and to multiple students who use their own devices. This paper presents the instructional environment from the instructor and student perspectives and discusses the interactions that are possible within an instructional cohort (i.e., the group of students taught by one instructor across all classrooms or devices). We discuss how this novel approach can scale to very large numbers of students, only limited by the number of interactions that are possible per student. The enrollment data show that the scalability of these approaches has caused a shift of all instruction in our program to these new instructional modes.
\end{abstract}

\section{Introduction}

International graduate students are important for many universities in the United States, the European Union, Great Britain, and Australia [1], in part to offset enrollment challenges at the undergraduate level [2]. Maintaining international enrollments has been challenging due to the current geopolitical environment [3]. Therefore, universities have put significant efforts into recruiting international graduate students.

New technologies in education have enabled universities to reach international students beyond those who are seeking a residential experience. Asynchronous online education is available to anyone who can connect to the Internet, but low persistence rates have limited the effectiveness of this approach $[4,5]$. Our prior work has described a novel mode of distance education that offers a high-quality learning environment for students and quality instruction from instructors who remain on the home campus and who teach synchronously to students abroad [6]. That work also reported on the effectiveness of this new teaching approach.

A key challenge in our prior system [6] is the limited scalability of using a single classroom. Specifically, that approach is limited to a single geographical location and requires all students to be physically present. In this paper, we describe how we have expanded the "Live Platform" in [6] to enable instruction to multiple remote classrooms. This extension to support multiple classrooms significantly increases the scalability of this new instructional approach. While a single instructor 
can teach to multiple classrooms, the interactions between instructor and student remain at a oneto-one level. Therefore, students retain the perception of individualized instruction. In addition, the participation of multiple classrooms during a class session can offer new types of inter-classroom learning.

In this paper, we briefly present the program for which we have developed this new instructional technology (Section 2). We then present the underlying technology that enables synchronous multi-classroom teaching to international students (Section 3). We also present a variant of this approach that enables students to engage in synchronous studies without needing to be present in the classroom. Finally, we present enrollment data that show that the presented instructional approaches have been fully adopted in our program (Section 4).

\section{Program Overview}

The program for which we have implemented this novel mode of instruction is the M.S. in Electrical and Computer Engineering (ECE). This program is a full 30-credit M.S. program that is split into 103 -credit courses. The degree that is issued at the completion of the program is identical to that offered to residential students in that program.

There are two variations of this program that we offer:

- Full Degree Program: Initially, the program was only offered as a full degree program delivered entirely via the Live Platform. In this modality, all 10 courses were taken by students remotely while remaining in their home country.

- 1+1 Program: As we discovered, there was significant interest in the market for a hybrid option of the degree program, where students start studying via the Live Platform before transitioning to the residential program on campus. In this hybrid option, students take 3 or 4 courses via the Live Platform and the remaining 7 or 6 courses on campus.

The main reasons for the popularity of this option are that students get a residential experience at lower cost (compared to a fully residential program), students have the option to participate in Optional Practical Training (OPT) after the completion of their program, and in some countries degree programs with substantial residential programs are viewed as preferred.

We currently offer both options to students depending on their location. The main market for this program is China (both options) and India (only 1+1 option).

The courses offered via the Live Platform contain the same content as the respective courses offered in the residential program. The only difference is that the course material for the Live Platform has been gone through an instructional design process to include planned interactions between instructor and students. Some of the residential courses have started to use the same course materials as for the Live Platform. Note that, while the courses are taught to students at international locations, there are no export control concerns since ITAR $\S 120.10$ exempts "information concerning general scientific, mathematical, or engineering principles commonly taught in schools, colleges, and universities" from export control. 


\section{Scalable Teaching and Learning Environment}

The Live Platform is the key innovation in the international degree program that we describe here. This section describes the various components and modes of interactions. The most important aspect of all these variations is that the instruction is synchronous, i.e., live. As such, this program is fundamentally different from online programs, which use recorded instruction. In particular, interactions between students and the instructor and among students are the norm.

\subsection{Cohort Configurations}

The Live Platform we use for instruction supports three fundamental configurations:

- One classroom: This configuration, shown in Figure 1(a), connects the instructor with one classroom as described in [6]. In this configuration, the instructor can directly interact with the students in the classroom, and students in the classroom can interact with their peers.

- Multiple classrooms: This configuration, shown in Figure 1(b), enables the instructor to interact with multiple classrooms at the same time. Each classroom perceives the instructor as dedicated to their location, but the instructor can monitor all classrooms. Interactions by students within the classroom and across classrooms is possible.

- Live-to-Device: This configuration, shown in Figure 1(c), does not require students to be physically present in a classroom. Students perceive the instructor teaching directly to them on their device. Each student can interact directly with the instructor and with peers.

In these configurations, the Live-to-Device approach can be viewed as a variation of the multiple classrooms scenario, where each student is in their own classroom. Of course, technology configuration in classrooms and Live-to-Device differ as we discuss below. However, treating all students as belonging to a classroom enables hybrid approaches, where classrooms and Live-to-Device students are combined. (We do not further discuss this hybrid configuration in this paper.)

In all configurations, students work together as cohorts and progress through the program as cohorts. Thus, the benefits of peer-interactions remain, independent of the technologies used.

\subsection{Instructor Environment}

The instructional environment provided to the instructor in the studio is nearly identical to that described in our prior work [6]. The main novelty of the approach described here is how an instructor can "see" the different classrooms (or individual students).

Figure 2 shows different views presented to the instructor. Figure 2(a) shows the view of one classroom. This perspective is used both in the old configuration with one classroom (Figure 1(a) [6]) and the new configuration with multiple classrooms (Figure 1(b)). In the latter scenario, the instructor view slowly cycles through all classrooms to allow the instructor to make eye contact with students.

Figure 2(b) shows the new perspective of the instructor when teaching to a group of Live-to-Device students. In this configuration, the instructor can see multiple students at the same time. The size of each student's face is roughly the same as in the classroom configuration. If more students take 


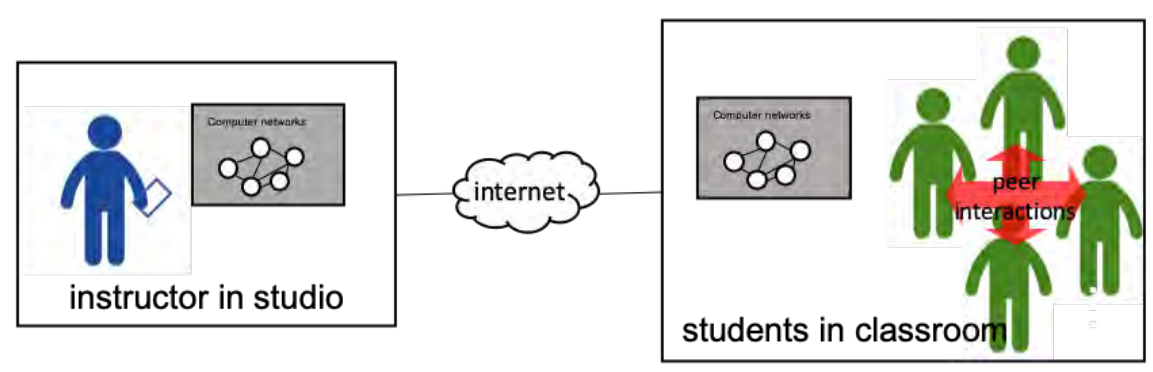

(a) Instructor teaching to one classroom [6].

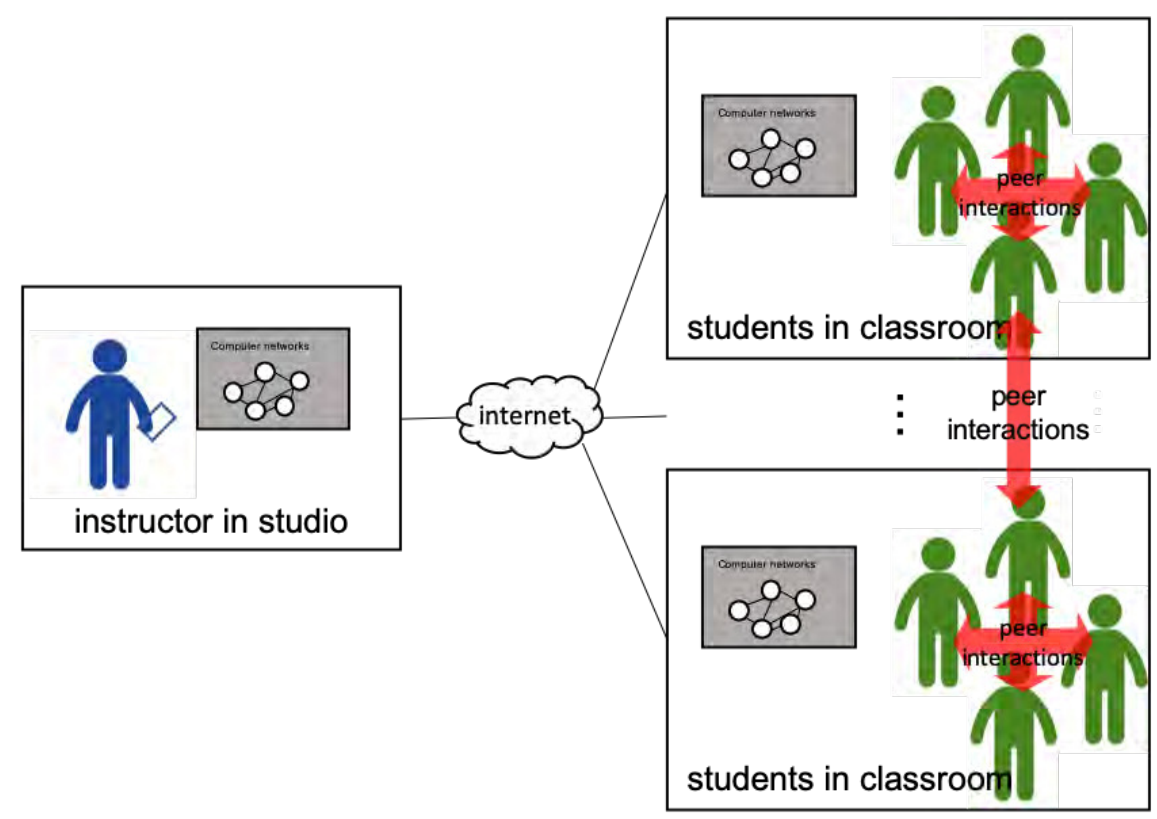

(b) Instructor teaching to multiple classrooms.

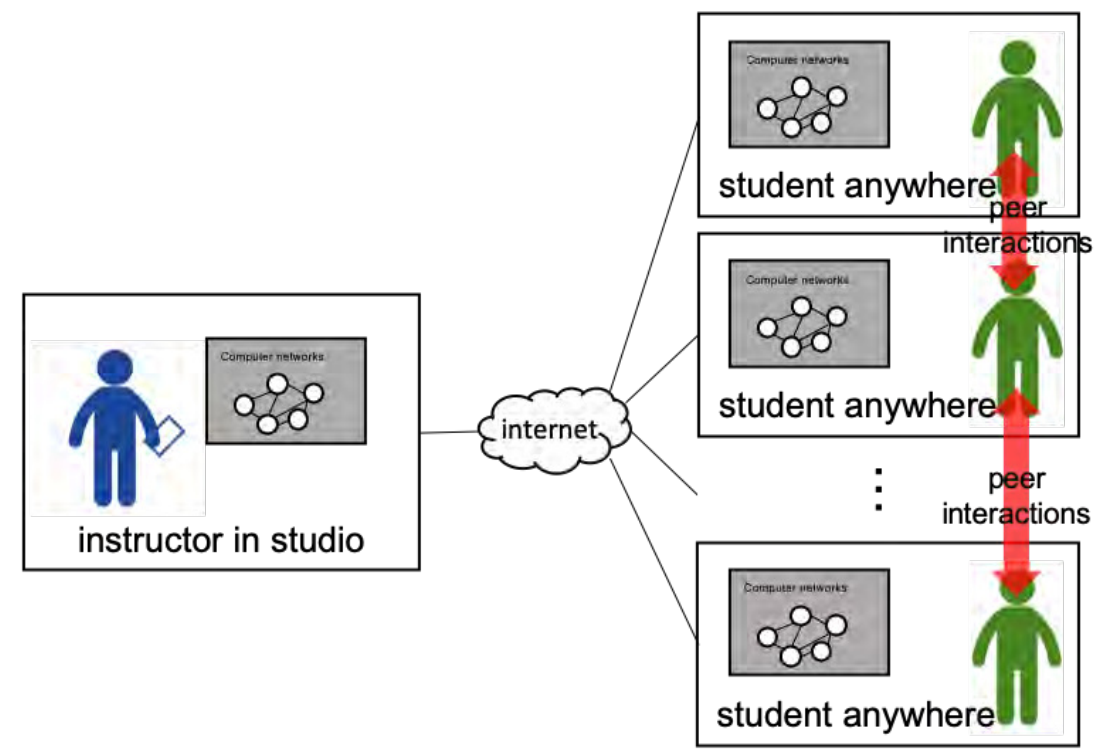

(c) Instructor teaching to multiple students using Live-to-Device.

Figure 1: Instructional configurations. 


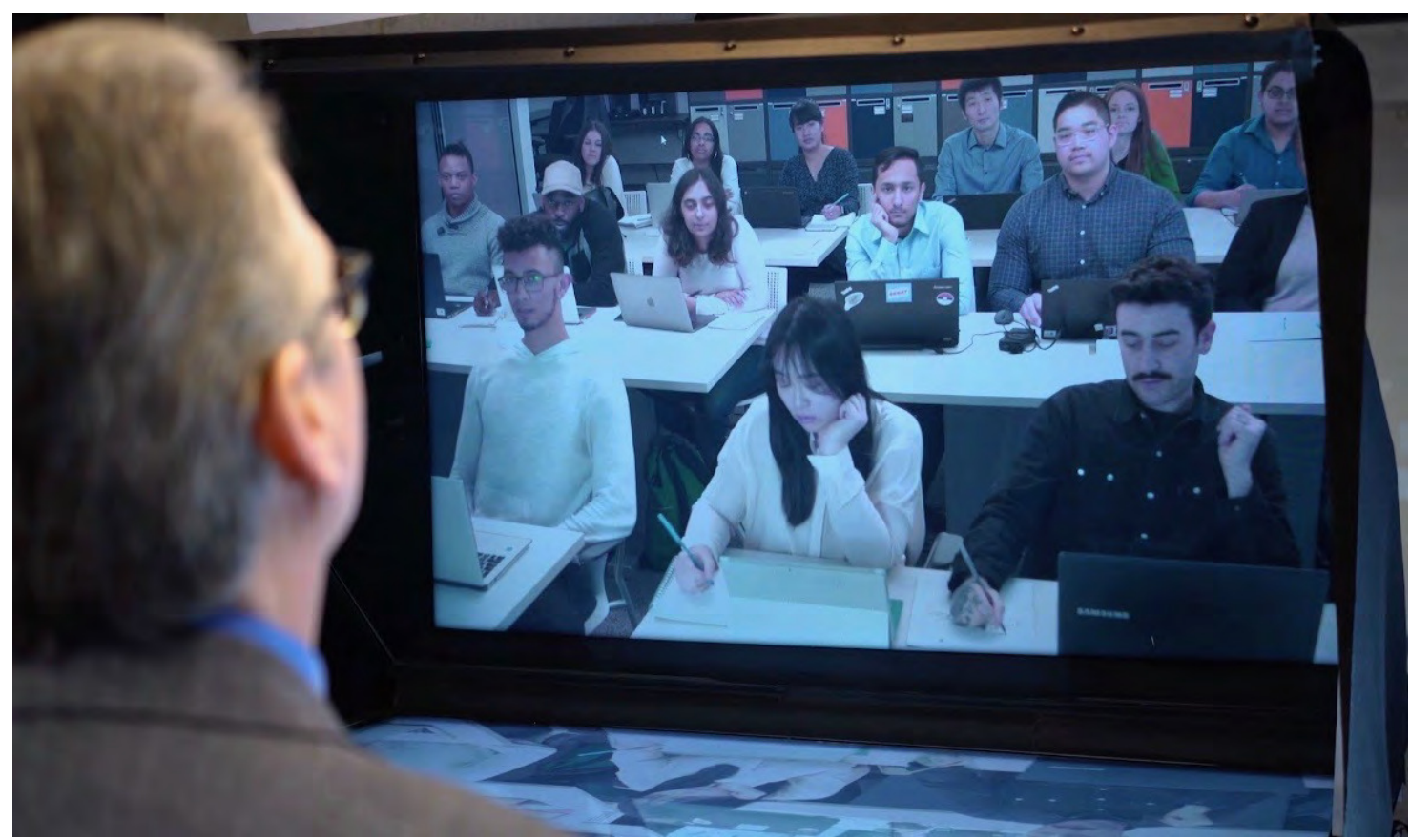

(a) Instructor view of a classroom [6].

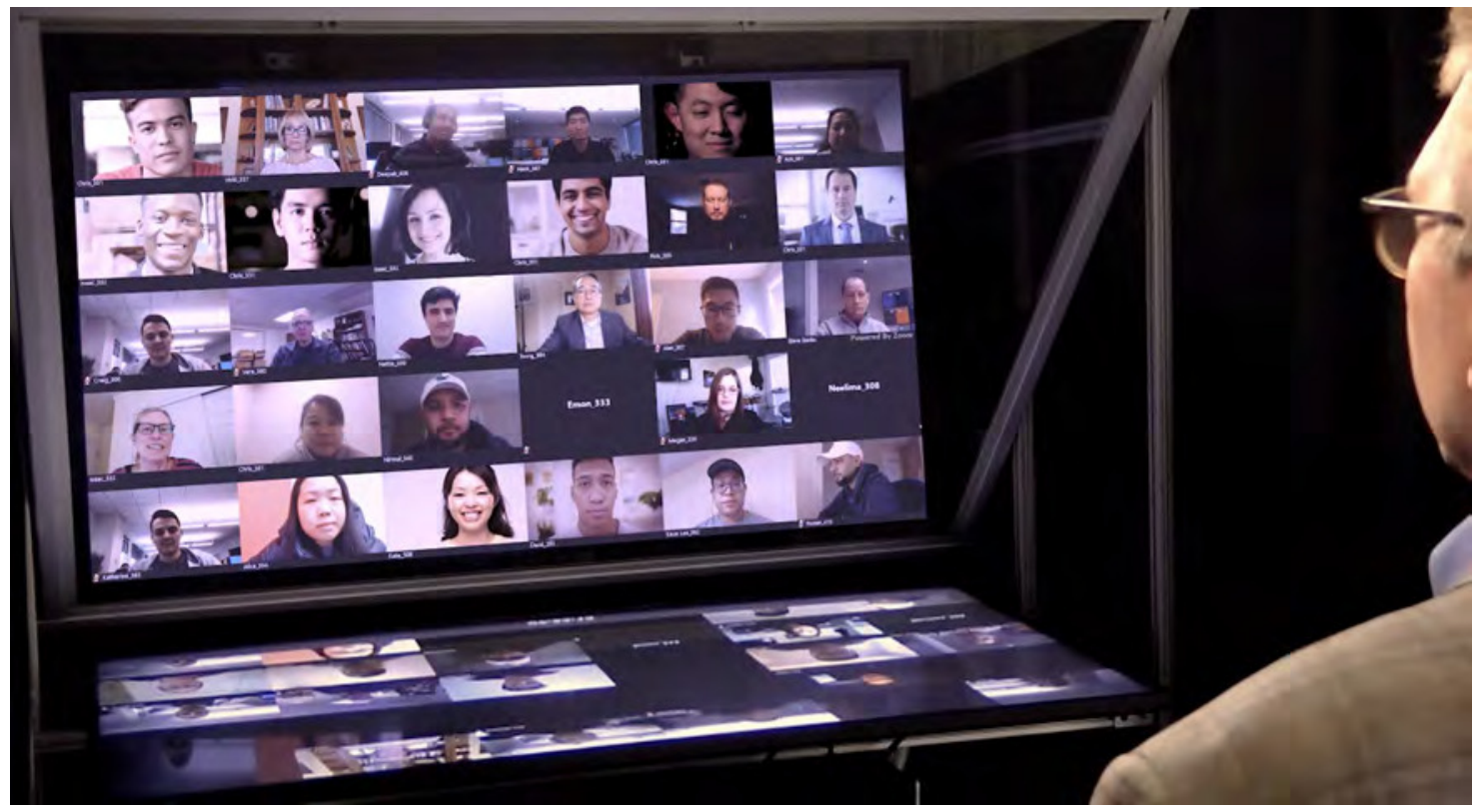

(b) Instructor of multiple Live-to-Device students.

Figure 2: Instructor views for different teaching configurations. 
the course than can reasonably fit on the instructor's screen, the students can be cycled as in the multiple-classroom configuration.

The instructional space for the instructor (interactive whiteboard, presentations with annotations, document camera, etc.) remains unchanged from [6].

\subsection{Student Environment}

Students engage in the program either via a classroom or on their own devices. The different perspectives are shown in Figure 3. Figure 3(a) shows the classroom as students see it. This view is the same in the single classroom configuration (Figure 1(a)) and in the multi-classroom configuration (Figure 1(b)). In both cases, the view of the instructor is persistent and content (whiteboard, presentation, document camera, etc.) is shown on the screens next to the instructor.

The persistent presentation of the instructor's image in the classroom creates the perception of "direct" and dedicated instruction to this classroom - even when the instructor sees a different classroom in his or her view (Figure 2(a)). As we discuss in Section 3.4, the views can be synchronized when interactions take place to ensure the interacting people can see each other.

Figure 3(b) shows the perspective of a student in the Live-to-Device configuration. The student sees the same content as in the classroom: a view of the instructor and a view of content. These feeds can be presented on multiple screens (as shown in Figure 3(b)) or on a single screen.

\subsection{Interactions}

The interactions that are possible in the instructional scenarios are similar to what is possible in the typical classroom. The studio/classroom interactions that were designed into the baseline scenario (Figure 1(a)) includes audio/video communication, shared whiteboard, etc. [6]. These functions were also replicated in the multiple-classroom scenario and in the Live-to-Device instruction.

The multiple locations (multiple classrooms or multiple student devices) present new challenges for interactions for audio and video so that interactivity can be supported:

- Audio: The audio distribution is designed to be "open" at all times to support the creation of a single learning community. That is, everyone can hear everyone else at all times. (The instructor has the ability to selectively disable audio to reduce interference from noisy sources.) Because of this configuration, inter-classroom (or inter-student) interactivity can be achieved easily.

- Video: There are multiple video streams that can be cycled full-screen (Figure 2(a)) or tiled (Figure 2(b)). Thus, the instructor may not be able to see all students at all times. The students using this platform have the ability to issue a "hand raise" via the learning management system (LMS) during the live lecture. In this case, the instructor gets notified of that event and, when selecting to respond to a particular hand raise, can make the system switch to the correct video stream that shows the student. The video of another classroom or student is shared during such interactions to engage students even when the instructor "talks with" 


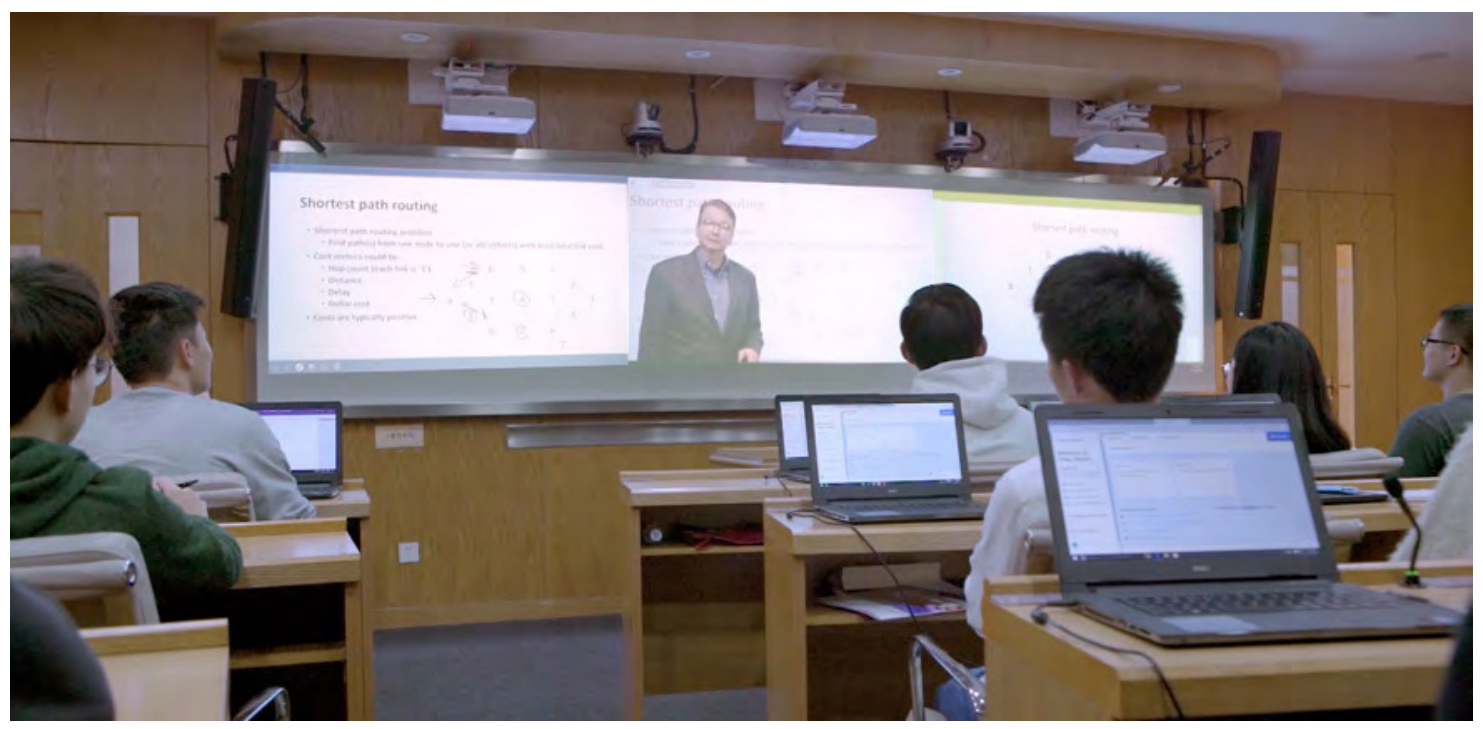

(a) Student view in classroom [6].

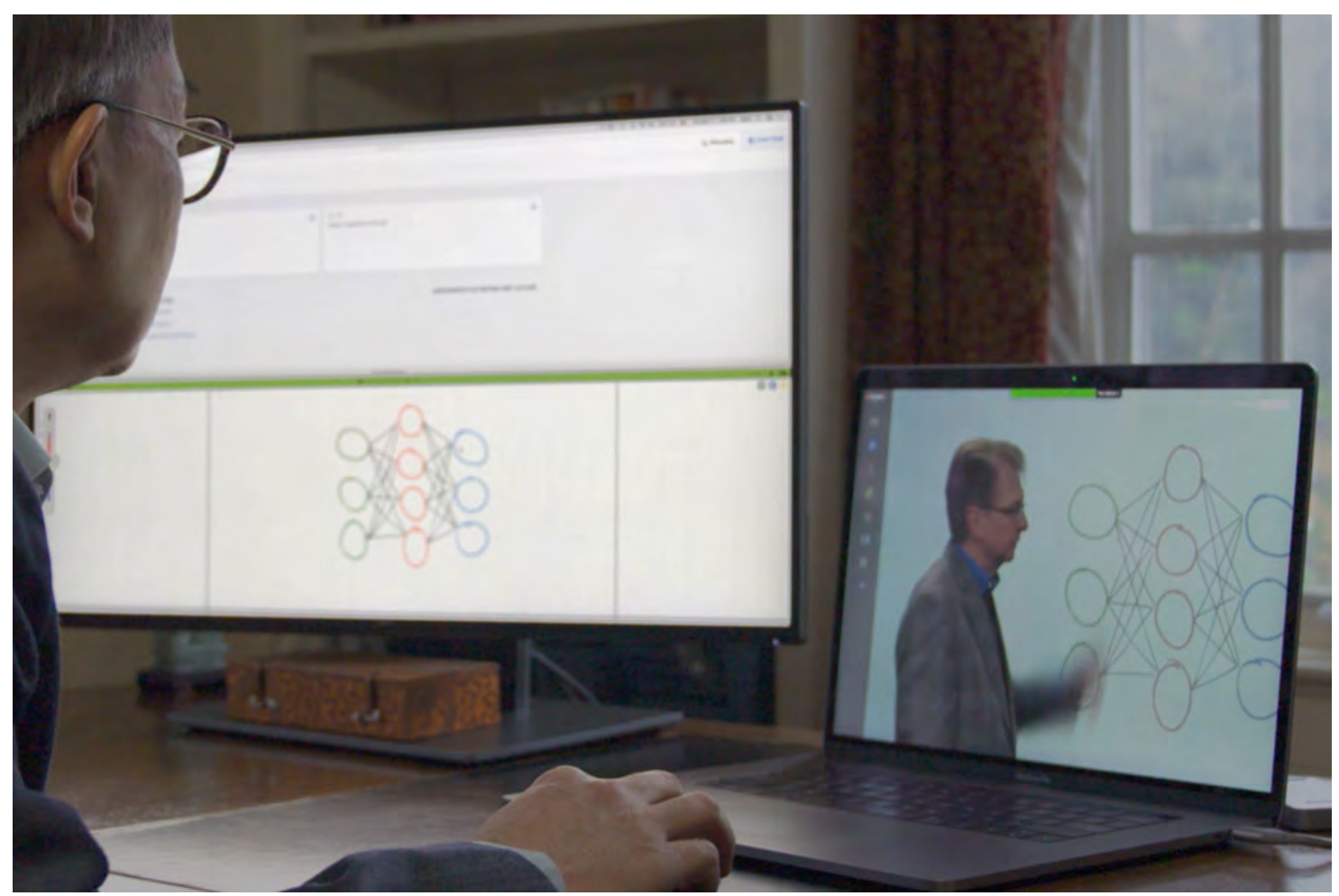

(b) Student view in Live-to-Device configuration.

Figure 3: Student views for different configurations. 
another classroom or student. Similarly, student-to-student interactions are possible between classrooms or devices.

These interactions achieve the main objective of this instructional environment:

- Live/synchronous instruction: All instruction is done in real-time and thus ensures that students can actively engage with the instructor at any point.

- Cohort-based experience: The engagement with other students in the same classroom, in other classrooms, or via other devices enables students to connect with their peers.

The work in [6] has shown that those characteristics of instruction lead to high persistence rates, which are otherwise hard to achieve in asynchronous "online" education.

\subsection{Scalability and Limitations}

The teaching and learning environment described above can scale to large cohorts of students. We consider scalability (i.e., how many students can be supported by this technology) from three perspectives:

- Student perspective: Each student sees the video of the instructor and can interact with the instructor and peers, independently of how many students are part of the cohort. The only practical limitation is in the number of interactions that are possible in very large courses (see below).

- Instructor perspective: The instructor can only see a limited number of students on the screen (see Figure 2(b)). Adding too many students on a single screen makes each face too small and changes the perception of the instructor from teaching to a small group of students to a "sea of faces." However, we can cycle a different group of students through the instructor's perspective. Since the instructor cannot see all students at the same time, they continue to perceive the classroom to be comparably small. Students who interact with the instructor (e.g., raise hand) are automatically swapped into the view of the instructor. Thus, there is no direct limit on how many students can be in a cohort from the perspective of the instructor. A limitation would be if there is a need for the instructor to monitor students carefully (e.g., during an exam) as discussed below.

- Technology perspective: The technology for this system is based on teleconferencing and learning management systems. Both of these technologies are mature and can support very large numbers of students (hundreds to thousands). Thus, there is no technical limitation on the number of students. As the number of students increases, some technological challenges need to be addressed (e.g., cumulative noise from open microphones), but those are manageable.

The limitations of this technology are twofold:

- Interactions: Within a course, there is a limited of opportunities for interactions. Even in a well-designed course with many interactive engagements per class, there are only so many students that the instructor can call on. As the number of students in the cohort increases, the average number of interactions that are possible for a student decreases correspondingly. 
Table 1: Enrollment data for different instructional modes in the program.

\begin{tabular}{|l|r|r|r|}
\cline { 2 - 4 } \multicolumn{1}{c|}{} & \multicolumn{3}{c|}{ Mode of instruction } \\
\hline Semester & One classroom & Multiple classrooms & Live-to-Device \\
\hline Fall 2017 & 8 & & \\
\hline Spring 2018 & 15 & & \\
\hline Summer 2018 & 23 & & \\
\hline Fall 2018 & & 36 & \\
\hline Spring 2019 & & 27 & 23 \\
\hline Summer 2019 & & 26 & 61 \\
\hline Fall 2019 & & & \\
\hline Spring 2020 & \multicolumn{2}{|c|}{ currently not possible in China } & \\
\hline
\end{tabular}

${ }^{1}$ Due to the coronavirus outbreak, classroom-based studies are currently not possible in China [7].

If the goal of a course is to provide an interactive environment (which differentiates the educational offering from an asynchronous online course), then the opportunities for interactions need to be reasonably high. For this reason, we limit the enrollment in a given course currently to 100 students.

- Monitoring: Some activities, such as exams, require close monitoring of students by the instructor. This is only possible when the instructor can see a given student much of the time. For very large cohorts, other approaches would be necessary (artificial intelligence analysis of video streams or additional proctors).

Despite these limitations, we believe that the technological foundation of our teaching and learning environment can serve to engage with a large number of students during synchronous instruction.

\section{Enrollment Data}

The enrollment numbers for this program are shown in Table 1. We started the program that is described here with a single classroom in Fall 2017 as described in [6]. After four semesters, the program expanded to multiple classrooms in Spring 2019. The Live-to-Device option was added in Fall 2019.

Note that one of the benefits of the Live-to-Device modality of instruction is that it does not require students to gather in one location. Due to the coronavirus outbreak in China, which is the main market for this program, no classroom instruction was possible for the Spring 2020 semester at the time of writing [7]. Therefore, all students in the program were switched to the Live-to-Device modality at the beginning of the Spring 2020 semester, and teaching and learning continue despite this significant public health emergency.

\section{Summary and Conclusions}

In this paper, we presented a novel approach to providing high-quality synchronous instruction to international students. The main novelty of this work is that one instructor can effectively 
teach synchronously to multiple classrooms or multiple students who use their own devices. The key aspects of the technology is the design of the instructor perspective, students perspective, and technological support for interactions. These interactions are modeled after those that are possible in a classroom and thus create the perception of active engagement for the instructor and the students. We describe the scalability of this teaching and learning technology, which is only limited by the number of per-student interactions that are possible during a given course when the cohort size becomes very large. The enrollment data of our program shows that this new, scalable approach to teaching has become the main modality of instruction.

\section{References}

[1] N. D. Grawe, Demographics and the Demand for Higher Education. Baltimore, MD: Johns Hopkins University Press, 2018.

[2] R. Seltzer, "High school graduates to drop in number and be increasingly diverse," Inside Higher Ed, Dec. 2016. [Online]. Available: https://www.insidehighered.com/news/2016/12/ 06/high-school-graduates-drop-number-and-be-increasingly-diverse

[3] B. L. Benderly, "A frayed welcome mat: Engineering deans struggle to attract foreign graduate students discouraged by the tone of U.S. policies and rethoric," ASEE Prism, pp. 24-29, Mar. 2019.

[4] M. L. Springer and M. T. Schuver, "Dwindling graduate student enrollments in distance-based programs: A researched-based exploration with underlying findings and premise," in 2018 ASEE Annual Conference \& Exposition, Salt Lake City, Utah, Jun. 2018.

[5] P. Bawa, "Retention in online courses: Exploring issues and solutions-a literature review," SAGE Open, vol. 6, no. 1, Jan. 2016.

[6] T. Wolf, C. V. Hollot, R. Tessier, B. Polivka, C. Hoehn-Saric, J. D. Kang, and K. Newman, "Synchronous cohort-based international education," in Proc. of ASEE Annual Conference \& Exposition, Tampa, FL, Jun. 2019.

[7] Y. Meiping, "More universities postpone spring semester," Shanghai Daily, Jan. 2020. 